\title{
All-trans retinoic acid inhibits the proliferation of SGC7901 cells by regulating caveolin-1 localization via the ERK/MAPK signaling pathway
}

\author{
SUMEI ZHANG $^{1 *}$, RUI SHI $^{2 *}$, SHAOLONG CHEN $^{1}$, XIANG WEI $^{1}$, QING ZHOU $^{1}$ and YUAN WANG ${ }^{1}$ \\ ${ }^{1}$ Laboratory of Molecular Biology and Department of Biochemistry, Key Laboratory of Gene Research of Anhui, \\ Hefei, Anhui 230032; ${ }^{2}$ Clinical Center of Tumor Therapy, The Lu'an People's Hospital, Lu'an, Anhui 237005, P.R. China
}

Received March 9, 2016; Accepted October 26, 2017

DOI: $10.3892 / \mathrm{ol} .2017 .7499$

\begin{abstract}
Caveolin-1 is a scaffold protein of caveolae in the mucosa of the gastrointestinal tract and acts as a tumor modulator by interacting with cell adhesion molecules and signaling receptors. Caveolin-1 stabilizes cell-cell and cellmatrix contacts and is a hallmark of a number of different types of human cancer, including gastric cancer. All-trans retinoic acid (ATRA), a derivative of vitamin A, has been demonstrated to exhibit tumor inhibitory effects in acute leukemia and certain types of solid tumor. In the present study, treatment with ATRA was demonstrated to inhibit the proliferation of gastric cancer cell line SGC7901, in a time- and dose-dependent manner. The markedly increased membrane localization of caveolin-1 was observed in the cells that were treated with $10 \mu \mathrm{mol} / 1$ ATRA for $>48 \mathrm{~h}$. In addition, it was observed that treatment with ATRA was able to regulate the level of phosphorylation of extracellular signal-regulated kinase (ERK). Therefore, the SGC7901 cells were treated with a specific agonist of ERK/mitogenactivated protein kinase (MAPK) investigate whether ATRA mediated its effects via the ERK/MAPK signaling pathway. The results of the present study demonstrated that ATRAinduced increase in membrane localization of caveolin-1 was reversed by treatment with a specific agonist of ERK/MAPK. Together, these results suggest that ATRA exhibits antigastric cancer effects. ATRA may regulate the membrane localization of caveolin-1 in order to inhibit the proliferation
\end{abstract}

Correspondence to: Dr Sumei Zhang or Professor Yuan Wang, Laboratory of Molecular Biology and Department of Biochemistry, Key Laboratory of Gene Research of Anhui, Hefei, Anhui 230032, P.R. China

E-mail: bzzsm@aliyun.com

E-mail: aydesm-1@163.com

*Contributed equally

Key words: all-trans retinoic acid, gastric cancer, SGC7901, caveolin-1 of SGC7901 cells. These effects of ATRA may be mediated by inhibiting the activation of ERK/MAPK signaling pathway. These results contribute to the current knowledge on the potential use of ATRA as therapy for solid tumors and provide further insight into the potential molecular mechanisms of ATRA action.

\section{Introduction}

The progression, invasion and metastasis of malignant tumor cells are associated with abnormal cell growth and loss of cell-cell adhesion (1). Caveolae have a specialized function in signal transduction, cell-cell stabilization and maintain interactions with cell matrix (2). Caveolin-1 is a pivotal scaffold protein of caveolae. As a marker protein of caveolae, caveolin-1 interacts with a number of signaling molecules to regulate cell proliferation, differentiation, apoptosis and cell adhesion by controlling the distribution of signaling protein in subcellular compartments and the activation status of these proteins $(3,4)$. However, the functions of caveolin-1 in pathogenesis, progression, invasion and metastasis of malignancies are controversial. A number of studies have demonstrated that caveolin-1 may serve as a tumor suppressor in stomach cancer (5-7).

All-trans retinoic acid (ATRA) is a derivative of vitamin A and has been used in oncotherapy. ATRA was first identified to exhibit anti-leukemic effects, with other studies demonstrating that ATRA also exhibits inhibitory effects on solid tumors, including gastric cancer (8-11). In order to determine the molecular mechanisms of ATRA on gastric cancer, the present study investigated whether ATRA served a suppressing tumor effect by regulating cell-cell adhesion potential and then regulating the proliferation of gastric cancer cells.

In the present study, ATRA was identified to significantly inhibit the proliferation of the gastric cancer cell line SGC7901. In addition, translocalization of caveolin-1 to the cell membrane in SGC7901 cells was promoted by ATRA treatment. Furthermore, ATRA treatment was able to affect the level of phosphorylation of extracellular signal-regulated kinase (ERK). When treated with the specific antagonist against ERK, the effect of ATRA treatment on caveolin-1 localization in SGC7901 cells was increased, whereas the 
effect of ATRA treatment was reversed by treatment with a specific agonist to ERK/mitogen-activated protein kinase (MAPK). These results suggested that the treatment with ATRA may adjust the membrane localization of caveolin-1 and inhibit the growth of SGC7901 gastric cancer cells. In addition, the aforementioned effects of ATRA in SGC7901 cells may be mediated by the ERK/MAPK signaling pathway.

\section{Materials and methods}

Cell culture. The gastric cancer cell line SCG7901 (American Type Culture Collection, Manassas, VA, USA) was cultured in Dulbecco's modified Eagle's medium (DMEM) supplemented with $10 \%$ fetal bovine serum (Clark Bioscience, Richmond, VA, USA), $100 \mathrm{U} / \mathrm{ml}$ penicillin and $100 \mu \mathrm{g} / \mathrm{ml}$ streptomycin and maintained in an incubator with a humidified atmosphere of $5 \% \mathrm{CO}_{2}$ at $37^{\circ} \mathrm{C}$. Upon reaching $80-90 \%$ confluence, the cells were trypsinized and sub-cultured.

Reagents. DMEM was purchased from Gibco (Thermo Fisher Scientific, Inc. Waltham, MA, USA). ATRA was purchased from Sigma-Aldrich (Merck KGaA; Darmstadt, Germany), dissolved in dimethyl sulfoxide (DMSO) and stored at a concentration of $10 \mathrm{mmol} / \mathrm{l}$. The antibodies were obtained from Santa Cruz Biotechnology, Inc. (Dallas, TX, USA). The remaining reagents were purchased from Sigma-Aldrich (Merck KGaA).

Cell proliferation assay using MTT. An MTT assay was performed to assess the effect of ATRA at different concentrations on SGC7901 cell proliferation according to standard protocol (12) in 96-well plates. SGC7901 cells (5,000 cells/well) were seeded into the wells and cultured. After reaching $\sim 50-60 \%$ confluence, 5, 10, 25, 50 and $100 \mu \mathrm{mol} / 1$ ATRA was added to the wells, respectively. The SGC7901 cells that were not treated with ATRA or DMSO were used as untreated cells (untreated cells). The cells treated with corresponding concentration of DMSO (1\%) were used as vehicle controls. A total of $20 \mu \mathrm{l} \mathrm{MTT}(1 \mathrm{mg} / \mathrm{ml})$ was added to each well following incubation at $37^{\circ} \mathrm{C}$ for 24,48 or $72 \mathrm{~h}$, respectively. Following an additional $4 \mathrm{~h}$ incubation at $37^{\circ} \mathrm{C}$, the medium was removed, and the crystals generated by cellular reduction were solubilized by adding $100 \mu \mathrm{l}$ DMSO. Following a $10 \mathrm{~min}$ incubation with agitation at $37^{\circ} \mathrm{C}$, the optical density (OD) was measured using a universal microplate reader (ELx800; BioTek Instruments, Inc., Winooski, VT, USA) at a wavelength of $570 \mathrm{~nm}$. The inhibition ratio was calculated as (OD of the control-OD of the unknown sample)/(OD of the control-OD of the blank control)x100\%. Each drug concentration was analyzed in four replicates, and the experiment was repeated in three times.

Immunofluorescence assay for labeling of caveolin-1 in distinct subcellular compartments. The cells ( $2 \times 10^{4}$ cells) were seeded onto sterile coverslips in a 12-well plate and were fixed with $4 \%$ paraformaldehyde for $20 \mathrm{~min}$ at room temperature when the cells grew to form a confluent monolayer following treatment with $10 \mu \mathrm{mol} / 1$ ATRA with or without phorbol 12-myristate 13-acetate (PMA, $1 \mu \mathrm{mol} / \mathrm{l}$ ) and PD98059
$(10 \mu \mathrm{mol} / \mathrm{l})$ for $72 \mathrm{~h}$ at $37^{\circ} \mathrm{C}$. Subsequently, the cells were incubated with $5 \%$ bovine serum albumin (Sigma-Aldrich; Merck KGaA, Darmstadt, Germany) in phosphate-buffered saline ( $\mathrm{pH}$ 7.4) for blocking for $2 \mathrm{~h}$ at room temperature and then were incubated overnight at $4{ }^{\circ} \mathrm{C}$ with the primary antibody against caveolin-1 (dilution, 1:50; cat no. sc-53564), followed by visualization with goat anti-mouse fluorescein isothiocyanate-coupled secondary antibody (dilution, 1:500; cat no. A0568) for $2 \mathrm{~h}$ at room temperature in a dark box. Cover slips were mounted, and the cells were imaged with a fluorescence microscope.

Analysis of caveolin-1 protein levels at distinct subcellular compartments using western blotting. Cell extracts were collected following treatment with $10 \mu \mathrm{mol} / \mathrm{l}$ ATRA for $72 \mathrm{~h}$ at $37^{\circ} \mathrm{C}$. For collection of cytoplasmic protein, the cells were lysed in lysis buffer [20 mM 4-(2-hydroxyethyl)1-piperazineethanesulfonic acid, $2 \mathrm{mM} \mathrm{MgCl}_{2}, 1 \mathrm{mM}$ EDTA, $2 \mathrm{mM}$ DTT, $5 \mu \mathrm{g} / \mathrm{ml}$ leupeptin, $1 \mathrm{mM}$ phenylmethanesulfonyl fluoride; $\mathrm{pH}$ 7.4] and then centrifuged at $16,000 \mathrm{x} \mathrm{g}$ for $20 \mathrm{~min}$ at $4^{\circ} \mathrm{C}$ to collect the supernatant. The membrane protein was obtained using Membrane Protein Extraction kit, according to the manufacturer's protocol. Total Protein Extraction kit was used to extract the total cellular protein, according to the manufacturer's protocol. The concentration of all the extracted protein was determined using the BCA method. Then the protein $(30 \mu \mathrm{g} /$ lane) was separated using SDS-PAGE $(12.5 \%$ gel) and transferred to polyvinylidene difluoride membranes. Following blocking in 5\% skimmed milk at room temperature for $2 \mathrm{~h}$, the membranes were incubated with the primary antibody against caveolin-1 (dilution, 1:500; cat no. sc-53564) at $4^{\circ} \mathrm{C}$ overnight, followed by incubation at room temperature for $2 \mathrm{~h}$ with horseradish peroxidase-conjugated secondary antibodies (dilution, 1:20,000; goat anti-mouse IgG; cat no. AP124P). Protein-antibody complexes were visualized by enhanced chemiluminescent detection system according to the manufacturer's protocol. $\beta$-actin (dilution, 1:1,000; cat. no. sc-47778, incubate at $4^{\circ} \mathrm{C}$ overnight) was used as the reference gene. The quantity of caveolin-1 relative to that of the reference protein $\beta$-actin was calculated with Quantity One (version, 4.6.2; Bio-Rad Laboratories, Inc., Hercules, CA, USA).

Western blot analysis for the detection of ERK signaling pathway activity. SGC7901 cells grown in 6-well cell culture plates were treated at $37^{\circ} \mathrm{C}$ with $10 \mu \mathrm{mol} / 1$ ATRA for 5, 15, 30 and $45 \mathrm{~min}, 1,2,4$ or $24 \mathrm{~h}$. Then, the cells were lysed with lysis buffer and the protein was collected, quantified and analyzed as aforementioned. The primary antibodies used were antibodies against phosphorylated (p)ERK (dilution, 1:500; cat no. sc- $7383,4^{\circ} \mathrm{C}$ overnight) or ERK (dilution, 1:500; cat no. sc-514302, $4^{\circ} \mathrm{C}$ overnight). Goat anti-mouse HRP-IgG was used as mentioned above (dilution, 1:20,000; cat no. AP124P, $2 \mathrm{~h}$ at room temperature).

Statistical analyses. Statistical analyses were performed using SPSS (version 16.0; SPSS, Inc., Chicago, IL, USA). One-way analysis of variance was used to analyze the difference among the distinct groups of gastric cancer cells. Multiple comparison between the groups was performed using the 
Table I. Inhibitory effect of ATRA at various concentrations on the proliferation of SGC7901 cells at $24 \mathrm{~h}$.

\begin{tabular}{lcc}
\hline Groups & $\mathrm{OD}_{570}$ & \% Inhibition \\
\hline Control & 0.212 & \\
Vehicle control & 0.191 & 2.47 \\
ATRA, $\mu$ mol/1 & & \\
5 & $0.186^{\mathrm{a}}$ & 16.07 \\
10 & $0.183^{\mathrm{a}}$ & 18.02 \\
25 & $0.167^{\mathrm{a}}$ & 28.01 \\
50 & $0.126^{\mathrm{a}}$ & 53.04 \\
100 & $0.076^{\mathrm{a}}$ & 83.93 \\
\hline
\end{tabular}

${ }^{\mathrm{a}} \mathrm{P}<0.05$ vs. vehicle control. ATRA, all-trans retinoic acid; OD, optical density.

Table II. Inhibitory effect of ATRA at various concentrations on the proliferation of SGC7901 cells at $48 \mathrm{~h}$.

\begin{tabular}{lcc}
\hline Groups & $\mathrm{OD}_{570}$ & \% Inhibition \\
\hline Control & 0.246 & \\
Vehicle control & 0.243 & 1.53 \\
ATRA, $\mu \mathrm{mol} / 1$ & & \\
5 & $0.208^{\mathrm{a}}$ & 19.25 \\
10 & $0.190^{\mathrm{a}}$ & 28.28 \\
25 & $0.184^{\mathrm{a}}$ & 31.6 \\
50 & $0.139^{\mathrm{a}}$ & 54.26 \\
100 & $0.067^{\mathrm{a}}$ & 91.31 \\
\hline
\end{tabular}

${ }^{\mathrm{a}} \mathrm{P}<0.05$ vs. vehicle control. ATRA, all-trans retinoic acid; OD, optical density.

Table III. Inhibitory effect of ATRA at various concentrations on the proliferation of SGC7901 cells at $72 \mathrm{~h}$.

\begin{tabular}{lcc}
\hline Groups & $\mathrm{OD}_{570}$ & \% Inhibition \\
\hline Control & 0.337 & \\
vehicle control & 0.335 & 1.45 \\
atra, $\mu \mathrm{mol} / 1$ & & \\
5 & $0.271^{\mathrm{a}}$ & 22.88 \\
10 & $0.252^{\mathrm{a}}$ & 29.77 \\
25 & $0.238^{\mathrm{a}}$ & 34.35 \\
50 & $0.166^{\mathrm{a}}$ & 59.68 \\
100 & $0.063^{\mathrm{a}}$ & 95.36 \\
\hline
\end{tabular}

${ }^{\text {a }} \mathrm{P}<0.05$ vs. vehicle control. ATRA, all-trans retinoic acid; OD, optical density.

Student-Newman-Keuls method. $\mathrm{P}<0.05$ was considered to indicate a statistically significant difference.
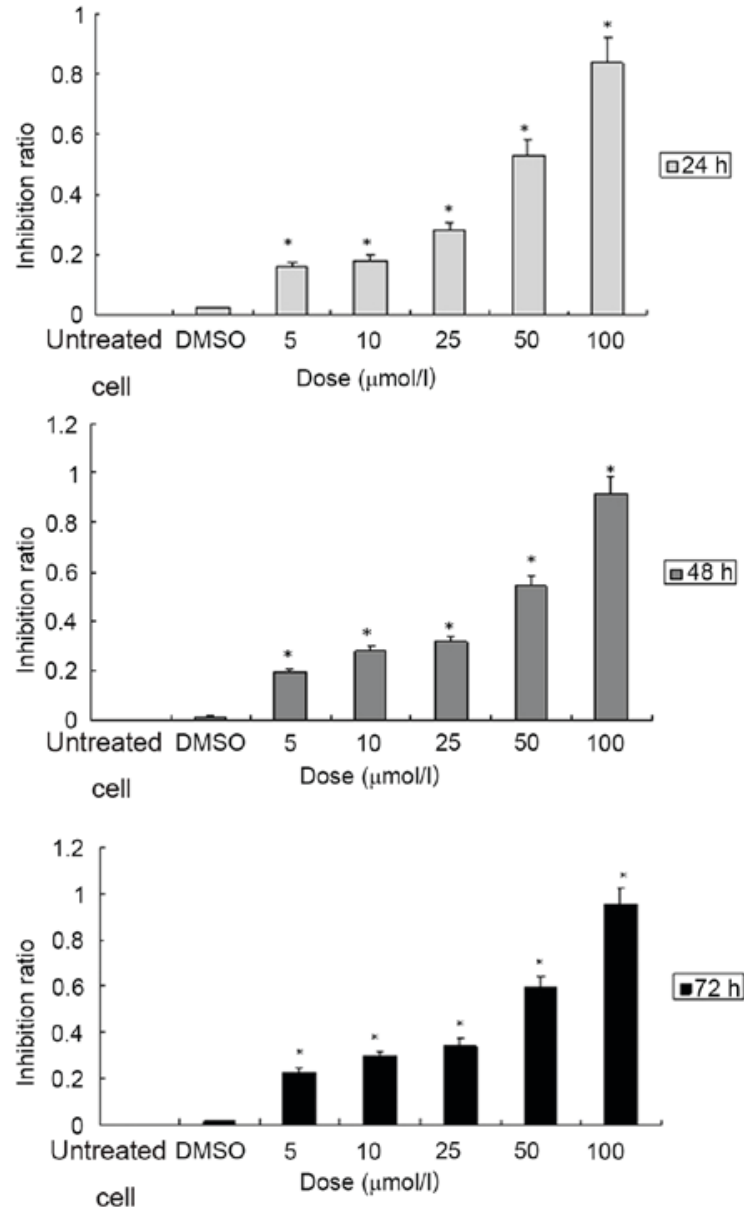

Figure 1. Inhibitory effect of ATRA on the growth of human gastric cancer SGC7901 cells at various concentrations for (A) 24, (B) 48 and (C) $72 \mathrm{~h}$. The SGC7901 cells were treated with ATRA at $5,10,25,50$ and $100 \mu \mathrm{mol} / 1$ for 24,48 and $72 \mathrm{~h}$, respectively. The vehicle control consisted of cells treated with DMSO. The data are presented as the mean \pm standard deviation of three independent experiments. The inhibition ratio of cells control is indicated as $0 .{ }^{*} \mathrm{P}<0.05$ vs. vehicle control. ATRA, all-trans retinoic acid; DMSO, dimethyl sulfoxide.
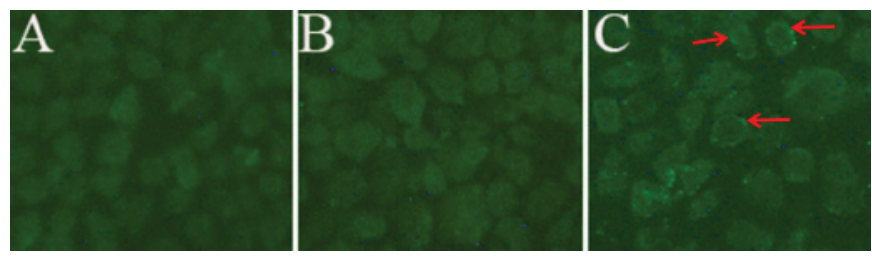

Figure 2. ATRA promotes the translocation of caveolin-1 to cell membrane in human gastric cancer SGC7901 cells. The SGC7901 cells were treated with $10 \mu \mathrm{mol} / \mathrm{l}$ ATRA for $72 \mathrm{~h}$ and the specific fluorescent staining of caveolin-1 was detected by immunofluorescence assay. (A) Staining of caveolin-1 in the cell membrane of untreated cells. (B) The location of caveolin-1 in cells in the vehicle control group. (C) There was a marked increase in the translocation of caveolin-1 to cell membranes in ATRA treated-SGC7901 cells when compared with untreated cells and vehicle control. The arrows indicate caveolin-1 staining on cell membranes. ATRA, all-trans retinoic acid.

\section{Results}

ATRA inhibits the proliferation of SGC7901 cells in adose-and time-dependent manner. The cells in the 96-well culture plate were treated with ATRA at various concentrations (5, 10, 25, 
A
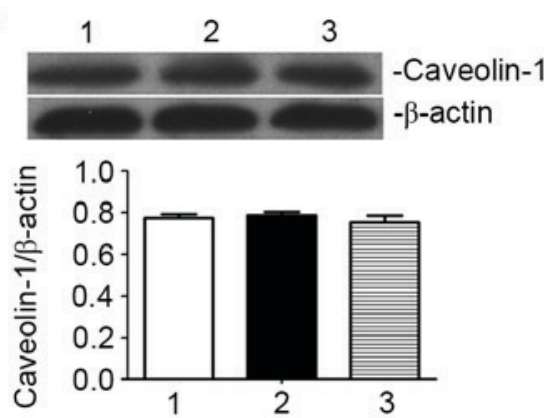

B

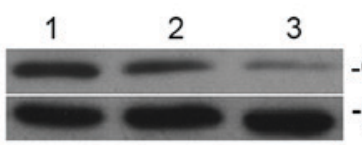

-Caveolin-1 $-\beta$-actin

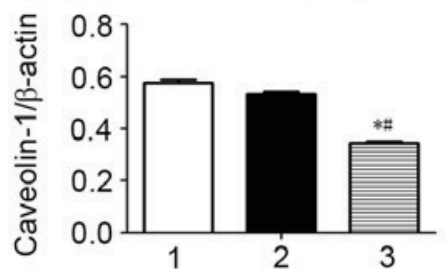

C
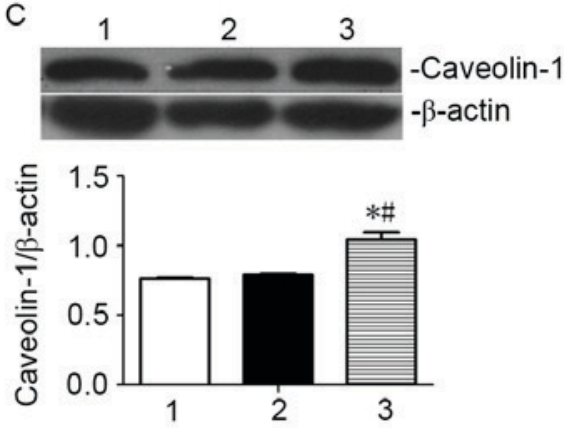

Figure 3. Western blot analysis was used to detect the total levels of caveolin-1, and membrane and cytosolic protein fractions in SGC7901 cells. (A) The total levels of caveolin-1 in SGC7901 cells. The total levels of caveolin-1 were not significantly different in ATRA-treated SGC7901 cells compared with the untreated cells or vehicle control. (B) The level of caveolin-1 in the cytosolic protein fraction in SGC7901 cells. The levels of caveolin-1 in the cytosolic fraction in ATRA-treated SGC7901 cells were significantly decreased compared with untreated cells or vehicle control. (C) The level of caveolin-1 in the membrane protein fraction in SGC7901 cells. The levels of caveolin-1 in the membrane fraction in ATRA-treated SGC7901 cell were significantly increased compared with untreated cells or vehicle control. Lanes: 1 , untreated cells; 2 , vehicle control; 3 , ATRA-treated cells. ${ }^{*} \mathrm{P}<0.05$, vs. untreated cells; ${ }^{\#} \mathrm{P}<0.05$ vs. vehicle control. ATRA, all-trans retinoic acid.

50 and $100 \mu \mathrm{mol} / \mathrm{l}$ ) for 24,48 or $72 \mathrm{~h}$, respectively. Cell viability was determined with a colorimetric MTT assay. The results indicated that treatment with ATRA was able to significantly inhibit the proliferation of SGC7901 cells when compared to the vehicle control group. When the cells were treated with ATRA at various concentrations of 5, 10, 25, 50 and $100 \mu \mathrm{mol} / 1$ for 24 , the $\%$ inhibition values were 16.07 , $18.02,28.01,53.04$ and $83.93 \%$ respectively. For $48 \mathrm{~h}$ treatment, the $\%$ inhibition ratios were $19.25,28.28,31.60,54.26$ and 91.31 , respectively. The $\%$ proliferation-inhibition were $22.88,29.77,34.35,59.68$ and $95.36 \%$ when treated for 72 h (Fig. 1; Tables I-III). In accordance with these results, $10 \mu \mathrm{mol} / 1$ ATRA was used to treat SGC7901 cells for $72 \mathrm{~h}$ in the subsequent experiments.

ATRA preferentially promotes the translocation of caveolin-1 to the cell membrane in SGC7901 cells. Following treatment of SGC7901 cells with $10 \mu \mathrm{mol} / 1$ ATRA for $72 \mathrm{~h}$, caveolin-1 localization and expression were determined by specific immunofluorescence labeling and western blot assay, respectively. As presented in Fig. 2, the fluorescent staining of caveolin-1 was identified in the cytoplasm and the cell membrane of the SGC7901 cells. Staining for caveolin-1 in the cell membrane was markedly increased, whereas the staining in the plasma was decreased when the cells were treated with ATRA for $72 \mathrm{~h}$ when compared to untreated cells and vehicle control. These results indicate that the cellular localization of caveolin-1 in SGC7901 cells is affected by ATRA treatment. Western blot analysis revealed that there was no significant change in the total levels of caveolin-1 when SGC7901 cells were ATRA (Fig. 3). The levels of caveolin-1 in the cytosolic protein fraction in SGC7901 cells were significantly increased compared with the vehicle control and untreated cells. By contrast, the levels of caveolin-1 in the cytosolic fraction in ATRA-treated SGC7901 cells were significantly decreased compared with the vehicle control and untreated cells (Fig. 3). These results indicate that ATRA treatment promotes the localization of caveolin-1 in the cell membrane, whereas ATRA treatment has no effects on the total expression levels of caveolin-1 in SGC7901 gastric cancer cells.
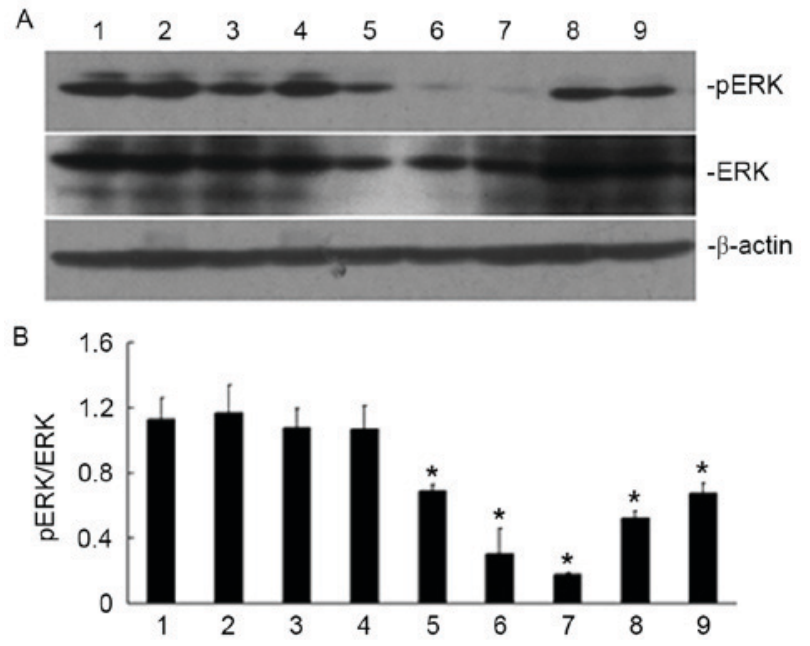

Figure 4. Effect of ATRA treatment duration on ERK phosphorylation in SGC790 1 gastric cancer cells. Treatment with ATRA was able to inhibit ERK phosphorylation when the cells were treated for $30 \mathrm{~min}$. (A) Specific bands for pERK and ERK in SGC7901 cells are shown in the western blots. (B) The ratio of pERK and ERK under various treatment conditions. Lanes: 1, untreated cells; 2, vehicle control; 3, ATRA-treated for $5 \mathrm{~min}$; 4, ATRA treatment for $15 \mathrm{~min} ; 5$, ATRA treatment for $30 \mathrm{~min}$; 6 , ATRA treatment for $45 \mathrm{~min}$; 7, ATRA treatment for $1 \mathrm{~h} ; 8$, ATRA treatment for $2 \mathrm{~h}$; 9, ATRA treatment for $4 \mathrm{~h}$. ${ }^{*} \mathrm{P}<0.05$, vs. untreated cells and vehicle control. ATRA, all-trans retinoic acid; ERK, extracellular signalregulated kinase; p, phosphorylated.

ATRA meditates its effects on the localization of caveolin-1 by inhibiting the activity of the ERK/MAPK signaling pathway. The SGC7901 cells were treated with $10 \mu \mathrm{mol} / 1$ ATRA for 5, 15, 30 and $45 \mathrm{~min}, 1,2,4$ or $24 \mathrm{~h}$, and the activity of the ERK signaling pathway was investigated by analyzing the phosphorylation levels of ERK. As presented in Fig. 4, the levels of pERK started to decrease when the cells were treated for $45 \mathrm{~min}$ compared with untreated cells, and the levels began to restore when the cells were treated longer than $2 \mathrm{~h}$. The observations led to the hypothesis that ATRA may meditate its effects on the regulation of caveolin-1 expression and localization via the ERK/MAPK signaling pathway. To investigate this hypothesis, a specific inhibitor (PD98059) and activator (PMA) of the ERK/MAPK 

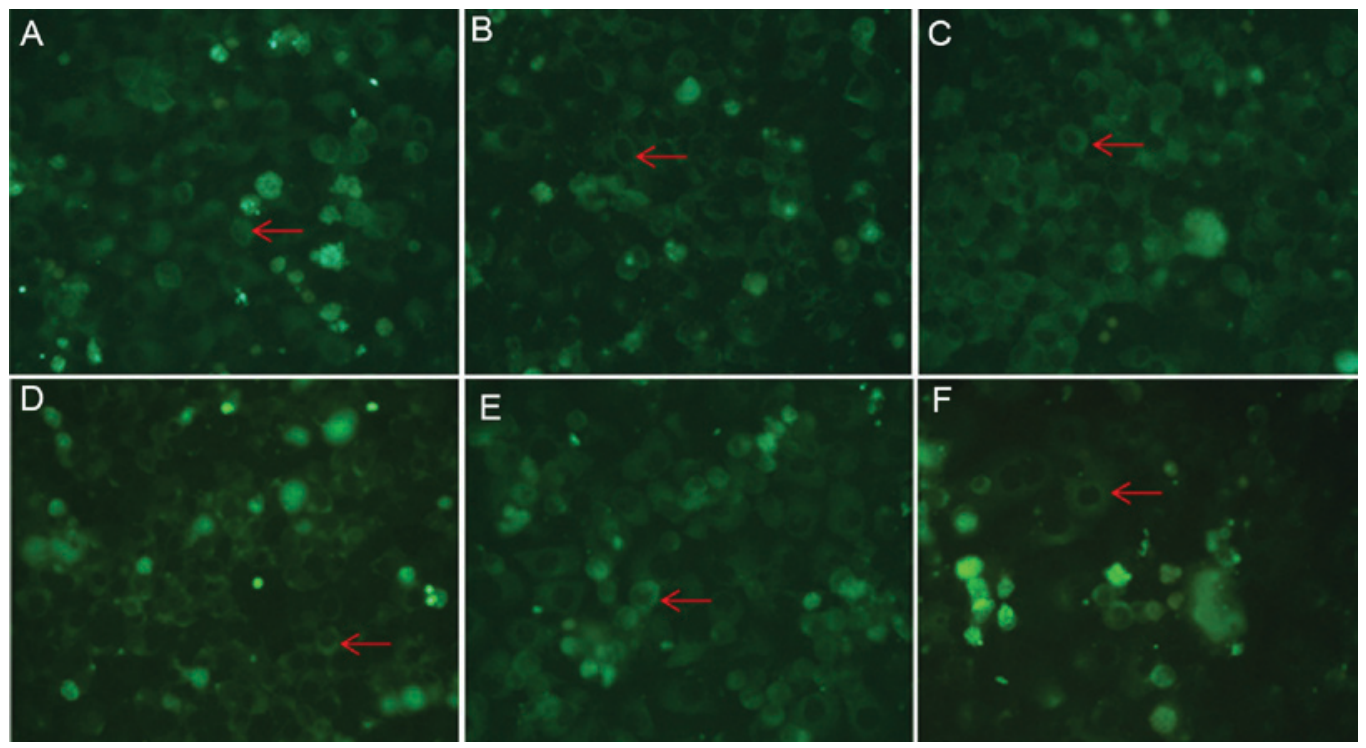

Figure 5. Specific immunofluorescent staining of caveolin-1 in SGC7901 cells. The specific caveolin-1 membrane staining was increased in SGC7901 cells treated with ATRA, PD98059 and a combination of ATRA and PD98059 compared to untreated cells, whereas PMA treatment was able to attenuate ATRAinduced caveolin-1 translocation to the cell membrane. (A) Untreated cells; (B) ATRA-treated cells; (C) PD98059-treated cells; (D) Cells treated with a combination of ATRA and PD98059; (E) PMA-treated cells; (F) Cells treated with a combination of ATRA and PMA. ATRA, all-trans retinoic acid; PMA, phorbol 12-myristate 13-acetate.

signaling pathway were added to the cell culture medium either in combination with ATRA or alone. Immunofluorescence assay revealed that the membrane localization of caveolin-1 was markedly increased in the cells that were treated with a combination of ATRA and PD98059 (a specific inhibitor of the ERK/MAPK signaling pathway), compared with the cells that were treated with ATRA or PD98059 alone. On the other hand, caveolin-1 aggregation induced by ATRA was attenuated in the PMA-treated cells compared with ATRA treated cells (Fig. 5).

\section{Discussion}

Gastric cancer is one of the most common types of malignant tumor in China and is the leading cause of cancer-associated mortality (13). As with other malignant tumors, multi-step processes and genetic alterations are proposed to be involved in the development of gastric cancer (14). Among these diverse processes, dysfunction of caveolae has been identified to be a critical factor involved in tumor development, invasion and metastasis (3).

Caveolae are membrane microdomains consisting of three major structural proteins, namely caveolin-1, -2 and -3 (15). Caveolin-1 is a principal protein for constructing caveolae and exerts roles in multiple cellular processes that are involved in tumor genesis signaling $(4,16)$. However, the tumor-associated functions of caveolin-1 are not fully clarified and are dependent on the type of tissue and stage of cancer (3). In gastric cancer, caveolin-1 has been identified as a tumor suppressor. A decrease or loss of caveolin-1 expression was demonstrated to be implicated in the pathogenesis of oncogenic transformation of cells $(5,6)$. Decreased expression of caveolin-1 was associated with increased occurrence of gastric cancer (5). Caveolin-1 expression resulted in cell cycle arrest at the G0-G1 phase of the cell cycle, thereby attenuating cell growth $(17,18)$. In addition, silencing of cavelin-1 in primary tumors promotes cell proliferation and enables excessive clonal expansion of tumor cells $(19,20)$. Therefore, caveolin-1 may be regarded as a prognostic biomarker for early detection, prediction and as a potential therapeutic target of gastric adenocarcinoma (21).

ATRA is derived from vitamin A and has been used in oncotherapy, particularly in the treatment of acute leukemia (8). In addition, previous studies have suggested that ATRA also regulate multiple cancer-associated processes in solid cancer cells, including cell proliferation, apoptosis, differentiation, migration and metastasis (22-24). The current study aimed to investigate the effects of ATRA treatment on the gastric cancer cell line SGC7901 and to determine whether caveolin-1 is involved in the effects of ATRA.

Cell proliferation assay revealed that in the SGC7901 cell line, treatment with ATRA led to a time- and dose-dependent decrease in cell proliferation (Fig. 1). The inhibition \% at $10 \mu \mathrm{mol} / \mathrm{l}$ was $18.02,28.28$ and $29.77 \%$ when the cells were treated with ATRA for 24, 48 and $72 \mathrm{~h}$, respectively. In the subsequent experiments of the present study, the SGC7901 cells were treated with ATRA at the concentration of $10 \mu \mathrm{mol} / 1$ ATRA for $72 \mathrm{~h}$.

Specific immunofluorescent staining was used to localize caveolin-1 in SGC7901 cells. The results of this assay demonstrated that caveolin-1 was located in the cytoplasm and on the cell membrane of the SGC7901 cells. ATRA-treated cells exhibited significantly increased membrane localization of caveolin-1 accompanied by decreased cytosolic localization, compared with the untreated controls (Fig. 2). To verify the results of the immunofluorescence experiments, western blot analysis was performed to detect the total levels of caveolin-1, and membrane and cytosolic protein fractions in SGC7901 cells. In the western blot assay, the quantity of caveolin-1 relative to that of the reference protein $\beta$-actin was calculated with Quantity One. A significantly increased level of caveolin-1 was observed in the cell membrane protein fraction in ATRA-treated 
cells, compared with the untreated control and vehicle control (Fig. 3C). At the same time, a significant decrease in the level of caveolin-1 in the cytosolic protein fraction was observed in the ATRA-treated cells compared with the untreated control and vehicle control (Fig. 3B). However, there was no noticeable difference in the total levels of caveolin-1 in ATRA-treated cells compared with control cells (Fig. 3A). Consistent results were observed from the immunofluorescence and western blot assays. The results of the present study suggest that ATRA is able to specifically promote the localization of caveolin-1 at the cell membrane, however ATRA has no effect on the total levels of caveolin-1.

The treatment of the SGC7901 cells with ATRA was able to inhibit the ERK/MAPK signaling pathway by decreasing the phosphorylation of ERK (Fig. 4). It was hypothesized that ATRA may regulate the localization of caveolin-1 by inhibiting the ERK/MAPK signaling pathway. To investigate the hypothesis, PMA (a specific agonist of the ERK/MAPK signaling pathway) and PD98059 (a inhibitor of the ERK/MAPK signaling pathway) were used to treat the SGC7901 cells, and immunofluorescent staining of caveolin-1 was performed. The results revealed that the membrane localization of caveolin-1 was increased when the cells were treated with the specific inhibitor PD98059 alone compared with untreated cells, and the effect was more apparent when the cells were treated with a combination of ATRA and PD98059 (Fig. 5C and D). The specific agonist PMA had the opposite effects compared with treatment with PD98059 alone. Treatment with PMA was able to attenuate ATRA-induced increase of membrane localization of caveolin-1 (Fig. 5E and F). These results may suggest that ATRA serves a function in adjusting the cellular localization of caveolin-1 via the ERK/MAPK signaling pathway.

In conclusion, the results of the present study indicate that treatment with ATRA was able to inhibit the proliferation of SGC7901 gastric cancer cells and the inhibitory effects of ATRA may be partially mediated by increasing caveolin-1 membrane localization. In addition, the effects of ATRA treatment in SGC7901 cells are partly mediated by inhibiting the activation of ERK.

\section{Acknowledgements}

The present study was supported by the Fund for Young Talents in College of Anhui Province (grant no. 2012SQRL067), National Natural Science Foundation of China (grant no. 81201907), National Natural Science Foundation of China (grant no. 81272399) and Research Fund for Doctor in Anhui Medical University (grant no. XJ201229).

\section{References}

1. Kamińska K, Szczylik C, Bielecka ZF, Bartnik E, Porta C, Lian F and Czarnecka AM: The role of the cell-cell interactions in cancer progression. J Cell Mol Med 19: 283-296, 2015.

2. Kovtun O, Tillu VA, Ariotti N, Parton RG and Collins BM: Cavin family proteins and the assembly of caveolae. J Cell Sci 128 : 1269-1278, 2015.

3. Cheng JP and Nichols BJ: Caveolae: One function or many? Trends Cell Biol 26: 177-189, 2016.

4. Fridolfsson HN, Roth DM, Insel PA and Patel HH: Regulation of intracellular signaling and function by caveolin. FASEB J 28: 3823-3831, 2014.
5. Sun GY, Wu JX, Wu JS, Pan YT and Jin R: Caveolin-1, E-cadherin and $\beta$-catenin in gastric carcinoma, precancerous tissues and chronic non-atrophic gastritis. Chin J Cancer Res 24: 23-28, 2012.

6. Xu L, Qu X, Li H, Li C, Liu J, Zheng H and Liu Y: Src/caveolin1-regulated EGFR activation antagonizes TRAIL-induced apoptosis in gastric cancer cells. Oncol Rep 32: 318-324, 2014.

7. Zhao X, He Y, Gao J, Fan L, Li Z, Yang G and Chen H: Caveolin-1 expression level in cancer associated fibroblasts predicts outcome in gastric cancer. PLoS One 8: e59102, 2013.

8. Schenk T, Stengel S and Zelent A: Unlocking the potential of retinoic acid in anticancer therapy. Br J Cancer 111: 2039-2045, 2014.

9. Ma HS, Greenblatt SM, Shirley CM, Duffield AS, Bruner JK, Li L, Nguyen B, Jung E, Aplan PD, Ghiaur G, et al: All-trans retinoic acid synergizes with FLT3 inhibition to eliminate FLT3/ITD+ leukemia stem cells in vitro and in vivo. Blood 127: 2867-2878, 2016.

10. Dutta A, Sen T and Chatterjee A: All-trans retinoic acid (ATRA) downregulates MMP-9 by modulating its regulatory molecules. Cell Adh Migr 4: 409-418, 2010.

11. Ju J, Wang N, Wang X and Chen F: A novel all-trans retinoic acid derivative inhibits proliferation and induces differentiation of human gastric carcinoma xenografts via up-regulating retinoic acid receptor $\beta$. Am J Transl Res 7: 856-865, 2015.

12. Scudiero DA, Shoemaker RH, Paull KD, Monks A, Tierney S, Nofziger TH, Currens MJ, Seniff D and Boyd MR: Evaluation of a soluble tetrazolium/formazan assay for cell growth and drug sensitivity in culture using human and other tumor cell lines. Cancer Res 48: 4827-4833, 1988.

13. Chen W, Zheng R, Baade PD, Zhang S, Zeng H, Bray F, Jemal A, Yu XQ and He J: Cancer statistics in China, 2015. CA Cancer J Clin 66: 115-132, 2016.

14. Jin K, Li T, van Dam H, Zhou F and Zhang L: Molecular insights into tumour metastasis: Tracing the dominant events. J Pathol 241: 567-577, 2016.

15. Fine SW, Lisanti MP, Galbiati F and Li M: Elevated expression of Caveolin-1 in adenocarcinoma of the colon. Am J Clin Pathol 115: 719-724, 2011.

16. Zhang Y, Hu XJ, Zhang LL, Sun LP, Yuan Y, Qu XJ and Liu YP: Interaction among Caveolin-1 genotypes (rs3807987/rs7804372), H. pylori infection, and risk of gastric cancer in a Chinese population. Tumour Biol 35: 1511-1516, 2014.

17. Burgermeister E, Xing X, Röcken C, Juhasz M, Chen J, Hiber M, Mair K, Shatz M, Liscovitch M, Schmid RM and Ebert MP: Differential expression and function of caveolin-1 in human gastric cancer progression. Cancer Res 67: 8519-8526, 2007.

18. Galbiati F, Volonté D, Liu J, Capozza F, Frank PG, Zhu L, Pestell RG and Lisanti MP: Caveolin-1 expression negatively regulates cell cycle progression by inducing $\mathrm{G}(0) / \mathrm{G}(1)$ arrest via a p53/p21(WAF1/Cip1)-dependent mechanism. Mol Biol Cell 12: 2229-2244, 2001.

19. Williams TM and Lisanti MP: The Caveolin genes: From cell biology to medicine. Ann Med 36: 584-595, 2004.

20. Hitkova I, Yuan G, Anderl F, Gerhard M, Kirchner T, Reu S, Röcken C, Schäfer C, Schmid RM, Vogelmann R, et al: Caveolin-1 protects B6129 mice against Helicobacter pylori gastritis. PloS Pathog 9: e1003251, 2013.

21. Kannan A, Krishnan A, Ali M, Subramaniam S, Halagowder D and Sivasithamparam ND: Caveolin-1 promotes gastric cancer progression by up-regulating epithelial to mesenchymal transition by crosstalk of signalling mechanisms under hypoxic condition. Eur J Cancer 50: 204-215, 2014.

22. Chu JH, Gao ZH and Qu XJ: Down-regulation of sphingosine kinase 2 (SphK2) increases the effects of all-trans-retinoic acid (ATRA) on colon cancer cells. Biomed Pharmacother 68: 10891097, 2014.

23. Sun R, Liu Y, Li SY, Shen S, Du XJ, Xu CF, Cao ZT, Bao Y, Zhu YH, Li YP, et al: Co-delivery of all-trans-retinoic acid and doxorubicin for cancer therapy with synergistic inhibition of cancerstem cells. Biomaterials 37: 405-414, 2015.

24. Lin E, Chen MC, Huang CY, Hsu SL, Huang WJ, Lin MS, Wu JC and Lin H: All-trans retinoic acid induces DU145 cell cycle arrest through Cdk5 activation. Cell Physiol Biochem 33: 1620-1630, 2014.

This work is licensed under a Creative Commons Attribution-NonCommercial-NoDerivatives 4.0 International (CC BY-NC-ND 4.0) License. 